УДК 615.322

\title{
ФЛАВОНОИДЫ, ТЕРПЕНОИДЫ И СТЕРОИДЫ LAGONYCHIUM FARCTUM (BANKS ET SOL.) BOBR. И RUBIA TRANSCAUCASICA GROSSH. ИЗ ФЛОРЫ АЗЕРБАЙДЖАНА
}

\author{
(C) И.С. Мовсумов, Т.А. Сулейманов, Э.А. Гараев*
}

\begin{abstract}
Азербайджанский медицинский университет, ул. Бакиханова, 23, Баку, AZ1022 (Азербайджан), e-mail: eldargar@mail.ru
\end{abstract}

Продолжая исследование растений из флоры Азербайджана, для выявления новых возможных источников биологически активных веществ впервые изучили компонентный состав Lagonychium farctum (Banks et Sol.) Bobr. (Mимозка выполненная), сем. Mimosaceae R.Br. (Мимозовые) и эндемичного вида для Азербайджана Rubia transcaucasica Grossh. (марена закавказская), сем. Rubiaceae Juss. (Мареновые). Из надземных частей L. farctum выделили и идентифицировали рутин и гиперозид, а из $R$. transcaucasica - рутин, гиперозид, олеаноловую кислоту и $\beta$-ситостерин.

Ключевые слова: Laqonychium farctum, Rubia transcaucasica, рутин, гиперозид, олеаноловая кислота.

\section{Введение}

Род мимозка включает только один вид $L$. farctum, распространенный в полупустынных областях, от Египта на юго-западе до Таджикистана на северо-востоке [1]. Отвар корней и плодов применяют при дизентерии. Листья и плоды в виде порошка применяют в Азербайджане как гемостатическое средство [2].

Род марена содержит около 55-60 видов, из них на Кавказе встречаются 4 вида, а в Азербайджане 3. R. transcaucasica является эндемиком для Азербайджана [3]. Корни рекомендуются как дополнительный источник получения препарата - экстракта корней $R$. tinctorium [4].

L. farctum (Banks et Sol.) Bobr. и R. transcaucasica Grossh. из флоры Азербайджана ранее в химическом и фармакологическом отношении не были изучены $[2,4]$.

Цель работы - выявление новых возможных источников биологически активных веществ из флоры Азербайджана.

\section{Экспериментальная часть}

Сырье L. farctum для исследования нами было заготовлено в начале июля 2014 года на Ахсуинском перевале Азербайджанской Республики. Сырье R. transcaucasica собрано в середине мая 2014 года в окрестностях г. Хачмаз Азербайджана. Для разделения соединений использовали различные методы хроматографии - бумажную (хроматографическая бумага - «Filtrak N17», Германия) и тонкослойную (TCX-

Мовсумов Исрафиль Солтан - доктор

фармацевтических наук, профессор кафедры фармацевтической химии, e-mail: eldargar@mail.ru Сулейманов Таир Абасали - доктор фармацевтических наук, профессор, заведующий кафедрой фармацевтической химии, e-mail: eldargar@mail.ru Гараев Эльдар Абдулла - доктор фармацевтических наук, доцент кафедры общей и токсикологической химии, e-mail: eldargar@mail.ru пластинки - «Sorbfil»). В качестве системы растворителей использовали: $\boldsymbol{н}$-бутанол - пиридин - вода, (6:4:3) (I), н-бутанол - уксусная кислота - вода, (4:1:5) (II), хлороформ-этилацетат, (1:1) (III), н-гексан - ацетон (4 : 1) (IV), ИК-спектры выделенных веществ снимали на приборе Varian (США). Температуру плавления и удельные вращения определяли на приборах «Smp 20 Stuart» (Великобрита-

\footnotetext{
* Автор, с которым следует вести переписку.
} 
ния) и «Rudolf Research Analytical» (США) соответственно. Моносахариды в гидролизате после нейтрализации с карбонитом бария обнаружили анилинфталовым реактивом (I), с последующим нагреванием.

0,8 кг воздушно-сухих измельченных надземных органов L. farctum экстрагировали дважды 85\%-ным этанолом в соотношении $1: 8$. Экстракты объединили, упаривали на роторном испарителе до водного остатка, обрабатывали хлороформом и этилацетатом. Из этилацетатного извлечения путем перекристаллизации из воды и этанола получили вещества 1 и 2.

1,0 кг воздушно-сухих измельченных надземных частей $R$. transcaucasica экстрагировали 95\% этанолом дважды. Экстракты объединяли, упаривали до 100-150 мл, добавили 100 мл воды и упаривали до водного остатка. Полученный водный остаток извлекали хлороформом и этилацетатом.

Из хлороформных извлечений после упаривания и обработки гексаном получили вещество $\mathbf{3}$, а из не растворимых в гексане остатков - вещество 4. Из этилацетатного извлечения путем перекристаллизации из воды и этанола получили вещества 5 и 6.

\section{Обсуждение результатов}

Вешество 1 - состав $\mathrm{C}_{27} \mathrm{H}_{30} \mathrm{O}_{16} \times 2 \mathrm{H}_{2} \mathrm{O}$, т.пл. $190-192{ }^{\circ} \mathrm{C}$ (из воды), [ $\left.\alpha\right]_{\mathrm{D}}{ }^{20}-31^{\circ}$ (с 0,35; диметилформамид). УФ-спектры: $\lambda_{\max }$ (метанол): 360, 268, 258 нм. $\mathrm{R}_{\mathrm{f}}$ 0,51 (растворитель 2). При полном кислотном гидролизе $\left(4 \% \mathrm{H}_{2} \mathrm{SO}_{4}, 4\right.$ ч) получили агликон (48\%) и моносахариды - D-глюкоза и L-рамноза. Т пл. агликона 308-310 ${ }^{\circ} \mathrm{C}$ (этанол). Агликон идентифицировали как кверцетин, а вещество 1 как рутин (кверцетин-3-О- $\beta$ D-глюкопиранозидо-(1 $\rightarrow 6)-\alpha$-L-рамнопиранозид).

Вещество 2 - состав $\mathrm{C}_{21} \mathrm{H}_{20} \mathrm{O}_{12}$, т.пл. $230-232{ }^{\circ} \mathrm{C}$ (этанол), $[\alpha]_{\mathrm{D}}{ }^{20}-58^{\circ}$ (с 0,1 ; метанол). УФ-спектры: $\lambda_{\max }$ (метанол): 354, 265, 255 нм. $\mathrm{R}_{\mathrm{f}}$ 0,67 (растворитель 2). При кислотном гидролизе получили кверцетин (64\%), в качестве моносахарида - D-галактоза (растворитель 1). Вещество 2 идентифицировали как гиперозид (кверцетин-3-O- $\beta$-D-галактопиранозид).

Вещество 3 - состав $\mathrm{C}_{29} \mathrm{H}_{50} \mathrm{O}$, т.пл. $148-149^{\circ} \mathrm{C}$ (этанол), $[\alpha]_{\mathrm{D}}{ }^{20}-40^{\circ}$ (с 0,25; хлороформ). $\mathrm{R}_{\mathrm{f}} 0,83$ (растворитель 4).Т.пл ацетата $128-130{ }^{\circ} \mathrm{C}$ (водный этанол). Реакция Либермана-Бурхарда положительна. Вещество 3 идентифицировали как $\beta$-ситостерин (ситостерол).

Вещество 4 - состав $\mathrm{C}_{30} \mathrm{H}_{48} \mathrm{O}_{3}$, т.пл. $303-305{ }^{\circ} \mathrm{C}$ (этанол), $[\alpha]_{\mathrm{D}}{ }^{20}-79^{\circ}$ (с 1,2; пиридин-метанол). $\mathrm{R}_{\mathrm{f}} 0,87$ (растворитель 3).ИК-спектры с олеаноловой кислотой идентичны. Вещество 4 отождествляли с олеаноловой кислотой ( $3 \beta$-гидрокси- $\Delta^{12}-28$-карбоксиолеанен).

На основании физико-химических свойств, спектральных и хроматографических данных, продуктов частичного и полного кислотного гидролиза вещество 5 идентифицировали как рутин, а вещество 6 - как гиперозид.

Рутин является фармакопейным препаратом и широко применяется в современной медицине [5].

Гиперозид (галактозид кверцетина) обладает кардиотоническим, желчегонным и гипоазотемическим действиями [6].

Олеаноловая кислота оказывает антимикробную, противосклеротическую, противовоспалительную, антиканцерогенную, гепатопротекторную, кардиостимилирующую и другие активности [7-11].

\section{Bblвodbl}

Впервые изучен флавоноидный состав Laqonychium farctum (Banks et Sol.) Bobr. и флавоноидные, тритерпеновые и стероидные составы Rubia transcaucasica Grossh. из флоры Азербайджана. Из L. farctum выделены и идентифицированы рутин $(1,5 \%)$ и гиперозид $(1,0 \%)$. Гиперозид ранее не обнаружен в надземных органах L. farctum.

Из надземных частей $R$. transcaucasica произрастающий в Азербайджане выделили олеаноловую кислоту $(0,3 \%), \beta$-ситостерин $(0,4 \%)$, рутин $(1,2 \%)$ и гиперозид $(0,8 \%)$.

\section{Список литературь}

1. Флора Азербайджана, сем. Rosaceae-Leguminozae. Баку, 1954. T. V. 580 c.

2. Растительные ресурсы СССР. Цветковые растения, их химический состав, использование. Сем. Hydrangeacae-Haloragaceae. Л., 1987. 321 c.

3. Флора Азербайджана, сем. Rubiaceae-Coтpositae. Баку, 1961. T. VIII. 688 c. 
4. Растительные ресурсы СССР. Цветковые растения, их химический состав, использование. Сем. CaprifoliacaePlantaginacae. Л., 1990. 326 c.

5. Машковский М.Д. Лекарственные средства. М., 2005. 1206 с.

6. Безрук П.И., Хаджай Я.И., Королев В.Ф. К фармакологии гиперозида и кверцетина // Материалы 9-й Всесоюзной конференции фармакологов. Свердловск, 1961. С. 22-23.

7. Kozai K., Miyake Y., Kohda H., Kametaka S., Yamasaki K., Suginaka H., Nakasaga N. Inhibition of Glycosiltransferase from Streptococcus mutans. Oleanolic Acid and ursolic Acid // Caries Res. 1987. Vol. 21. N2. Pp. 104-108.

8. Yin M.C., Chan K.C. Nonezymatic antioxydative and antiglycative effects of oleanolic acid and ursolic acid// J. Agric. Food Chem. 2007. Vol. 55. N17. Pp. 104-108.

9. Liu J. Oleanolic acid and ursolic acid: Research perspectives // J. of Etnopharmacology. 2005. Vol. 100. Pp. 92-94.

10. Liu J. Pharmacolgy of oleanolic acid and ursolic acid // J. of Etnopharmacology. 1995. Vol. 49. Pp. 57-68.

11. Gao D.W., Li Q., Li Y., Liu Z.W., Fan Y.S., Han Z.S., Li J., Li K., Antidiabetic potential oleanolic acid from Ligusrum licidum Ait. Can // J. Physiol. Pharmacol. 2007. Vol. 85. Pp. 1076-1083.

Поступило в редакцию 25 ноября 2015 г.

После переработки 28 мая 2016 г. 
Movsumov I.S., Suleymanov T.A., Garaev E.A.* FLAVONOIDS, TERPENOIDS AND STEROIDS OF LAQONYCHIUM FARCTUM (BANKS ET SOL.) BOBR. AND RUBIA TRANSCAUCASICA GROSSH. IN AZERBAIJAN

Azerbaijan Medical University, ul. Bakikhanova, 23, Baku, AZ1022 (Azerbaijan), e-mail: eldargar@mail.ru

To identify possible sources of new biologically active substances in Azerbaijan for the first time studied the component composition Laqonychium farctum (BanksetSol.) Bobr. (Mimosaceae) and endemic species for Azerbaijan Rubia transcaucasica Grossh. (Rubiaceae Juss.) From the overground parts of L. farctum isolated and identifed rutin and hyperoside, and from $R$. transcaucasica rutin, hyperoside, oleanolic acid and $\beta$-sitosterol.

Keywords: Loqanychium farctum, Rubia transcaucasica, rutin, hyperoside, oleanolic acid.

\section{References}

1. Flora Azerbaidzhana, Semeistva Rosaceae-Leguminozae [Flora of Azerbaijan, Family Rosaceae-Leguminozae]. Baku, 1954, vol. V, 580 p. (in Russ.).

2. Rastitel'nye resursy SSSR.Tsvetkovye rasteniia, ikh chimicheskii sostav, ispol'zovanie. Semeistva HydrangeacaeHaloragaceae. [Plant resuources of the USSR, flowering plants, their chemical compositiation, use. Family Hydrangeacae-Haloragaceae]. Leningrad, 1987, 321 p. (in Russ.).

3. Flora Azerbaidzhana, Semeistva Rubiaceae-Compositae [Flora of Azerbaijan, Family Rubiaceae-Compositae]. Baku, 1961, vol. VIII, 688 p. (in Russ.).

4. Rastitel'nye resursy SSSR. Tsvetkovye rasteniia, ikh chimicheskii sostav, ispol'zovanie. Semeistva CaprifoliacaePlantaginacae. [Plant resuources of the USSR, flowering plants, their chemical compositiation, use. Family Caprifoliacae-Plantaginacae]. Leningrad, 1990, 326 p. (in Russ.).

5. Mashkovski M.D. Lekarstvennie sredstva, 2005, 1206 p. (in Russ.).

6. Bezryk P.I., Khadzhai Ia.I., Korolev V.F. Materialy 9-Vsesoiznoi konferensii farmakologov. [Proceedings of the $9^{\text {th }}$ All-Union Conference of Pharmacology]. Sverdlovsk, 1961, pp. 22-23. (in Russ.).

7. Kozai K., Miyake Y., Kohda H., Kametaka S., Yamasaki K., Suginaka H., Nakasaga N. Caries Res. 1987, vol. 21, no. 2, pp. 104-108.

8. Yin M.C., Chan K.C. J. Agric. Food Chem., 2007, vol. 55, no. 17, pp. 104-108.

9. Liu J. J. of Etnopharmacology, 2005, vol. 100, pp. 92-94.

10. Liu J. J. of Etnopharmacology, 1995, vol. 49, pp. 57-68.

11. Gao D.W., Li Q., Li Y., Liu Z.W., Fan Y.S., Han Z.S., Li J., Li K., J. Physiol. Pharmacol., 2007, vol. 85, pp. 10761083.

Received November 25, 2015

Revised May 28, 2016

\footnotetext{
* Corresponding author.
} 